\title{
Alcohol Harm: Beyond the Body to the Body Politic
}

\author{
Ricardo González MD PhD DrSc
}

\begin{abstract}
In light of the World Health Organization's declaration that nondependent drinking contributes more to the global burden of alcohol-related disease than does drinking by those who meet diagnostic criteria for dependence, this paper argues that clinicians, researchers and decision-makers need to consider microsocial and macrosocial impacts of alcohol use, not just addiction and clinical effects on individuals meeting diagnostic criteria at the extreme high end of the alcohol-use spectrum. It suggests some qualitative dimensions to further define social or low-risk drinking and proposes that all drinking beyond that be described as harmful, because of its impacts on personal, community and population health.
\end{abstract}

KEYWORDS Alcohol-related disorders, burden of illness, International Classification of Diseases

\section{ALCOHOL AS A HEALTH PROBLEM}

Globally, harmful alcohol use as defined by the World Health Organization (WHO) accounts for $3.2 \%$ of all deaths annually, 12 years of reduced life expectancy and $4 \%$ of the total years of productive life lost to disability and premature death. Impact is even greater in the Americas, where alcohol-related disability-adjusted life years lost represent $9.7 \%$ of the total, over double the global figure.[1] In Latin America, harmful alcohol use is the most important disease risk factor among the 27 monitored by the WHO and the Pan American Health Organization (PAHO), exceeding, among others, high blood pressure, smoking, lead exposure, dietary fat, obesity, LDL cholesterol, unsafe water, physical inactivity, and lack of fruit and vegetables.[2] In fact, it is associated with more than 60 diseases, including some surprises, such as breast cancer and osteoporosis, particularly in men.[1]

The estimated economic burden of harmful alcohol use globally was estimated between $\$ 210$ and $\$ 665$ billion in 2002, according to a review of cost studies addressing a range of factors including not only health care costs but others, such as law enforcement, property damage and productivity losses.[3]

On the microsocial level-between this broader macrosocial impact on society and the direct effect on the physical and mental health of the drinker-is the effect of alcohol use on those who love, live with or work with the drinker. Some aspects of these problems are commonly appreciated and well-studied, such as injury (intentional or otherwise), incest, rape, child abuse, posttraumatic stress, anxiety, depression and suicide. As with environmental tobacco smoke, those near the user's drinking suffer the effects; when the user's drinking becomes a chief preoccupation in life, a loved one can become literally co-dependent. Rather than second-hand smoke, the loved one is exposed to constant anxiety, activating psychoneuroimmunological pathways and contributing to development of myriad conditions from high blood pressure and gastroduodenal ulcers to cardiac arrhythmias, obesity, hyperlipidemia, thromboses, hyperthyroidism, diabetes and psoriasis.[4]
Failing to recognize such impacts of harmful alcohol use denies the existence of the hypothalamo-pituitary-adrenal axis, the essence of what were formerly called psychosomatic and are now included in ICD-10 as somatoform disorders.[5,6] Overlooking the microsocial effects, often by both researchers and clinicians, also leads to further underestimates of the full impact of harmful alcohol use.

\section{THROUGH A POPULATION HEALTH LENS}

Specialists in prevention and control of alcohol-related health problems have long been critical of an overriding focus on addiction and the consequent tendency to ignore the broader impacts of alcohol use mentioned above.[7] In 2005, the 58 World Health Assembly (WHA) Secretariat issued a report on public health problems caused by harmful alcohol use, highlighting how this insistence on equating alcohol-related harm with addiction or alcohol dependence overlooks the fact that the social costs arising from alcohol use by non-dependent drinkers far outweigh those generated by dependent alcoholics.[8] It is easy to see how the cumulative social, medical and economic impact of non-dependent drinkers can be greater than that of diagnosed alcoholics when one bears in mind that, even in the regions of the world with highest alcohol consumption, heavy drinkers constitute no more than a small minority $(9.1-11.2 \%)$ of drinkers.[1]

Based on this assessment, the WHO passed Resolution 58.26 on alcohol-related public health problems, emphasizing ways that "patterns, context and overall level of alcohol consumption influence the health of the population as a whole," and calling on member states to develop strategies and programs to reduce all negative health and social consequences of harmful alcohol use, not just addiction.[9] Conceptually and operationally, the WHA Secretariat's report and subsequent WHO resolution are vitally important for comprehensive alcohol-abuse prevention, treatment and control programs. Their greatest contribution is establishing the significance of the population health impact of alcohol consumption by people who are not alcohol-dependent. [8,9]

This conceptualization goes far beyond the idea of addiction as the only alcohol-related risk to individuals, families and communities. Yet even today, it is not consistently reflected in the terminology used by WHO to classify alcohol-related harm. In particular, usage in the WHO's main clinical diagnosis guide, the International Classification of Diseases (ICD-10), is in conflict with that used in all WHO documents addressing alcohol as a public health issue.[5]

Hence, these classifications should be reviewed and subject to changes that both reflect and encourage a broader approach to alcohol use as a population health problem. The discussion is timely as a series of workshops regarding the eleventh revision of the ICD will be held in 2011 in WHO member countries, including Cuba. 
LIMITS TO THE ABSTINENCE-ADDICTION CONTINUUM Health professionals involved in addiction treatment and prevention generally accept WHO terminology laid out in ICD-10 and the WHO Lexicon of Alcohol and Drug Terms. These definitions of individual alcohol-related behavior and clinical diagnostic criteria range from abstinence through social or low-risk, at-risk and harmful use, culminating in alcohol dependency (Table 1). $[5,10]$ A person may be placed on this continuum according to his/her responses to the first three questions of the Alcohol Use Disorders Identification Test (AUDIT) questionnaire: AQ1) How often do you have a drink containing alcohol? AQ2) How many drinks containing alcohol do you have on a typical day when you are drinking? AQ3) How often do you have six or more drinks on one occasion?[11]

If the answer to question AQ1 is Never, the individual is classified abstinent (no health risk). According to the WHO Lexicon of Alcohol and Drugs, abstinence is refraining from drinking alcohol, on principle or for other reasons.[10] Those who answer anything other than Never to AQ1 are then classified as social or non-social drinkers, depending on their responses to the other questions.

This paper argues that, regardless of whether or not dependence exists, all drinking beyond the level described in $\mathrm{WHO}$ terminology as social use is harmful and contributes to the global burden of alcohol-related disease.

Social (low-risk) drinking The definition of social drinking developed at a time when the primary concern of scientists working in prevention and control of problem drinking was the addictive effect of ethanol in its various forms. This led to criteria based on quantity and frequency of consumption, and establishment of a threshold marking levels at which metabolic changes leading to dependence occur, that is, 210 $\mathrm{g}$ weekly for men and $140 \mathrm{~g}$ weekly for women. Consumption equal to or below this threshold is considered low risk by default according to current $\mathrm{WHO}$ and $\mathrm{PAHO}$ definitions, which classify consumption above the threshold as "hazardous".[12] The number of drinks involved varies from country to country, so the AUDIT questionnaire includes specific instructions for adapting item scoring to prevailing average drink sizes.[11]

Non-social (harmful) drinking Harmful use and alcohol dependence syndrome are the two clinical diagnoses related to alcohol use in ICD-10. Harmful use in ICD-10 is defined by harm to the individual's physical or mental health.[5]

At the highest end of the consumption continuum, the $\mathrm{WHO}$ prefers the term alcohol dependence syndrome to the more traditional but rather ambiguous term, alcoholism, for the condition in which an individual experiences a powerful and uncontrollable desire for alcohol that takes primacy over all other activities and obligations he or she previously valued.[10] In ICD-10, alcohol dependence is described as "a cluster of behavioral, cognitive, and physiological phenomena," the central characteristic of which is that alcohol use "takes on a much higher priority for a given individual than other behaviors that once had greater value." Clinical diagnosis of alcohol dependence syndrome is based on the appearance of three of the following six phenomena together in an individual within the previous year:

- increased tolerance

- withdrawal symptoms on stopping (not always present)

- persistent drinking despite obvious harm

- preoccupation with alcohol overriding other interests

- reduced ability to stop drinking once started

- overwhelming compulsion to drink.[5]

\section{PROPOSING COMPREHENSIVE CRITERIA}

In light of current WHO thinking, definitions of social drinking should include, in addition to quantity and frequency as assessed by AUDIT, qualitative criteria such as:

- conscious intention to avoid intoxication

- preference for drinking with meals or on special occasions

- not allowing alcohol to become a characteristic of one's lifestyle or to affect one's financial status

- not violating medical advice or cultural norms

- not affecting family, school, work or community responsibilities (Table 1).

Adding these qualifiers creates a more restrictive definition of social use, proposed here because there can be real risks to health below current quantitative thresholds marking the division between social and non-social drinking. Many people currently considered social drinkers are in fact at risk when they drink irresponsibly (e.g., driving a motor vehicle); when they drink inappropriately, as while performing any client service, increasing the likelihood of substandard performance or violent conflict; when they find themselves unable to limit drinking once they start; when they drink in order to get drunk; when they drink against medical advice or in the presence of contraindications such as pregnancy or youth; when they drink in order to numb disturbing emotions.

With the exception of drinking against medical advice, the essence of these patterns is in drinking to the point of intoxication, a condition which, when temporarily "decapitating" the prefrontal supraorbital region, takes the individual back 15 million years in the evolution of the species, since this region and its higher-order functions are not present in any other animal, however advanced.[13] In common with all drugs that similarly alter consciousness, personality and behavior, drunkenness produces a tragic effect on virtues, principles and ethical-moral norms, by blocking the inhibition of subcortical functions, particularly in the limbic system. In Freudian terms, the individual is left with no Superego, a weakened Ego and the Id brutally in charge.[14,15] In effect, alcohol performs a sort of prefrontal lobotomy, disengaging the higher cortical functions of judgment and conscience.

The term "low-risk drinking" is preferable to "social drinking" because the latter has so long included behaviors such as those listed above, which are far from low risk. Any consumption outside of this combined quantitative-qualitative definition should be considered harmful use.

To be consistent with this position, the term "harmful" is also preferable to the euphemistic "non-social." However, the WHO also uses "harmful use" in Resolution 58.26 to refer to the entire range of public health effects of alcohol use, limiting it to 
Table 1: Amended Framework for Assessing Alcohol-related Harm

\begin{tabular}{|c|c|c|c|c|c|}
\hline Alcohol Use & No & & Yes & & \\
\hline Terminology, WHO & Ahotingnen & Conioluro & & Harmful use $\mathrm{e}^{\mathrm{ab}}$ & \\
\hline Lexicon and ICD-10 & Austunerice & Social use & Hazardous or at-risk use ${ }^{a}$ & Harmful use ${ }^{d}$ & Alcohol dependence $^{d}$ \\
\hline Quantitative criteria & $\begin{array}{l}\text { Zero } \\
\text { consumption }^{a}\end{array}$ & $\begin{array}{l}\text { AUDIT score }<8^{c} \\
\leq 210 \mathrm{~g} / \mathrm{wk}(\mathrm{M}) \\
\leq 140 \mathrm{~g} / \mathrm{wk}(\mathrm{F})^{\mathrm{e}}\end{array}$ & $\begin{array}{l}\text { AUDIT score } 8-15^{c} \\
>210 \mathrm{~g} / \mathrm{wk}(\mathrm{M}) \\
>140 \mathrm{~g} / \mathrm{wk}(\mathrm{F})^{\mathrm{e}}\end{array}$ & AUDIT score $16-19^{c}$ & $\begin{array}{l}\text { AUDIT score } \geq 20^{c} \\
\text { ICD-10: } 3 \text { of } 6 \text { criteria } \\
\text { below met in previous } \\
\text { year }^{d}\end{array}$ \\
\hline
\end{tabular}

M: Male F: Female N/A: Not applicable $\square$ Current $\square$ Proposed

aWHO 2005

bWHO Lexicon (Babor 1994)

${ }^{\mathrm{C} A U D I T}$ (Babor 2001)

dICD-10

eWHO 1980

"public health effects... without prejudice to religious beliefs and cultural norms in any way".[9] This presents the problem of confusing the public health sense of "harmful" with the ICD-10 diagnostic category, harmful use, which is explicitly limited to consumption at a level that causes actual damage to the individual's physical or mental health, without regard to social or other consequences.[5]

While this is understandable in a manual intended to support clinical diagnosis in individuals, these two diagnoses-harmful use and alcohol dependence syndrome-are just the tip of the iceberg for public health. Spanish translations of the term get around this problem by using two different words, perjudicial for harmful use as a clinical diagnosis and nocivo for the more global concept used in public health discourse. $[16,17]$ One could propose yet another term in English to cover the public health implications of alcohol, or simply rename the clinical category "medically harmful use".

Whether establishing clinical diagnoses or assessing risk of alcohol-related harm, thresholds for frequency and amount of consumption need to be complemented in practice by qualitative aspects, including harm to physical, mental or social wellbeing; loss of control over alcohol use; and whether or not the individual or his/her loved ones identify his/her drinking as problematic, as in the Cuban adaptation of Chapter V of ICD-10.[6]

To understand and address the true dimensions of the alcoholharm iceberg, then, we must look at the full range of its negative consequences for individuals, families and communities, as well as the total population health impact of drinking beyond the amounts and behavioral limits that define low risk. 1 -

\section{REFERENCES}

1. Rehm J, Monteiro M. Alcohol consumption and burden of disease in the Americas: implications for alcohol policy. Rev Panam Salud Publica. 2005 Oct-Nov;18(4-5):241-8.

2. Roses M. La Salud Mental: una prioridad de salud pública en las Américas. Rev Panam Salud Pública. 2005 Oct-Nov;18(4-5):223-5.

3. Baumberg B. The global economic burden of alcohol: a review and some suggestions. Drug Alcohol Rev. 2006;25(6):537-51.

4. Arce S. Inmunología Clínica y Estrés. Havana: Editorial Ciencias Médicas; 2007.
5. The ICD-10 Classification of Mental and Behavioral Disorders. Clinical descriptions and diagnostic guidelines. Geneva: World Health Organization; 1992

6. Otero A, Ravelo V, Echazabal A, Calzadilla L, Duarte F, Magriñat JM. Tercer Glosario Cubano de Psiquiatría. Havana: Editorial Hospital Psiquiátrico de la Habana; 2008. Chapter V. GC-3.

7. González R, Galán G. La declaración de Brasilia: reflexiones sobre sus pautas para el enfrentamiento a los problemas relacionados con el alcohol [Internet]. Rev Hosp Psiq Ha- bana. 2007 Jan-Apr [cited 2010 August 5]. Available from: http://www.revistahph.sld.cu/ hph0107/hph010707.htm

8. Public health problems caused by harmful use of alcohol. Report by the Secretariat. 58th World Health Assembly. Report No.: A58/18. Geneva: World Health Organization; 2005.

9. Public Health Problems Caused by Harmful Use of Alcohol. Resolution 58.26, 58th World Health Assembly. Geneva: World Health Organization; 2005.

10. Babor T, Campbell R, Room R, Saunders $\mathrm{J}$, editors. Lexicon of Alcohol and Drug 
Terms. Geneva: World Health Organization; 1994.

11. Babor TF, Higgins-Biddle JC, Saunders JB, Monteiro MG. Alcohol Use Disorders Identification Test. Guidelines for Use in Primary Care (AUDIT). 2nd ed. Geneva: World Health Organization; 2001.

12. Problems related to alcohol consumption. Report of a WHO Expert Committee. WHO Technical Report Series, No. 650. Geneva: World Health Organization; 1980.

13. Acarín N. El cerebro del Rey. Havana: Editorial Científico Técnica; 2008.

14. Hurd Y. Perspectives on Current Directions in the Neurobiology of Addiction Disorders Rele- vant to Genetic Risk Factors. CNS Spectr. 2006 Nov;11(11):855-62.

15. Hoppes K. The Application of Mindfulness Based Cognitive Interventions in the Treatment of Co-occurring Addictive and Mood Disorders. CNS Spectr. 2006 Nov;11(11):829-51.

16. Problemas de salud publica causados por el uso nocivo del alcohol. Resolución 58.26, 58a Asamblea Mundial de la Salud. Geneva: World Health Organization; 2005.

17. Clasificación Estadística Internacional de Enfermedades y Problemas Relacionados con la Salud. 10ma Revisión, CIE-10. Washington: Pan-American Health Organization; 1995.

\section{THE AUTHOR}

Ricardo Angel González Menéndez (isaric@infomed.sld.cu), psychiatrist. Consulting professor, Enrique Cabrera Medical School, Medical University of Havana, Havana, Cuba.

Submitted: July 5, 2010

Approved for publication: October 19, 2010

Disclosures: None 